\title{
Laser Induced Fluorescence Studies of Blood Plasma and Tumor Tissue of Men with Prostate Tumors
}

\author{
Liana Ramishvili', Irma Bochorishvili', Nino Gabunia ${ }^{2}$, Zurab Kuchukashvili1, \\ Manana Gordeziani' ${ }^{1}$, Teimuraz Chigogidze², Ana Khazaradze1, Zaza Melikishvili3, \\ Nanuli Kotrikadze ${ }^{1}$ \\ ${ }^{1}$ Department of Biology, Faculty of Exact and Natural Sciences, Ivane Javakhishvili Tbilisi State University, \\ Tbilisi, Georgia \\ ${ }^{2}$ Department of Urology, Faculty of Medicine, Ivane Javakhishvili Tbilisi State University, Tbilisi, Georgia \\ ${ }^{3}$ Institute of Cybernetics of the Academy of Sciences, Tbilisi, Georgia \\ Email: nkotrikadze@gmail.com
}

Received 25 July 2014; revised 20 August 2014; accepted 14 September 2014

Copyright (C) 2014 by authors and Scientific Research Publishing Inc.

This work is licensed under the Creative Commons Attribution International License (CC BY).

http://creativecommons.org/licenses/by/4.0/

(c) (i) Open Access

\section{Abstract}

Objectives: Fluorescence spectroscopy which can be used for optical tissue diagnosis of tumor pathology deserves special interest. The purpose of the work was to study blood plasma and tumor tissue of men with different forms of prostate tumors by using laser induced fluorescence. Blood plasma and tumor tissue of the patients with benign hyperplasia of the prostate (BHP), BHP with inflammation, BHP with high grade PIN (BHP with HGPIN) and adenocarcinoma of prostate (CaP) have been studied. Results: In case of blood plasma fluorescence, intensity of the plasma proteins corresponding peak ( $340-360 \mathrm{~nm}$ ) was increasing in the following manner: control group $\rightarrow$ BHP $\rightarrow$ BHP with HGPIN $\rightarrow$ CaP. The intensity of the nicotinamide coenzymes correspond peak (440 $460 \mathrm{~nm}$ ) was increased in case of BHP with HGPIN and CaP patients, but decreased in case of BHP, compared to control. In case of tumor tissue, the changes of the collagen peak $(390-400 \mathrm{~nm}) \mathrm{in}$ tensity have been revealed in all cases of prostate tumor tissues. These alterations point to altered collagen biosynthesis levels in different tumor tissues, that reflects the structural changes and characteristics of malignant transformation. Also the changes of the nicotinamide coenzymes peak $(440-460 \mathrm{~nm})$ intensity in all spectra of tumor tissues were observed. The highest intensity of the peak was observed in the spectra of BHP with HGPIN and in prostate cancer tissue. Conclusions: Alterations of the coenzymes peak intensities perfectly reflect and are in accordance with the specific energy metabolism of prostate epithelial cells. Normalization of fluorescent spectra from different forms of prostate tumor tissues has shown that, each form has typical spectral shape and ratio of fluorescence peaks intensities. 


\section{Keywords}

\section{Prostate Tumors, Fluorescence, Endogenous Fluorophores, Energy Metabolism}

\section{Introduction}

Prostate cancer is the most common cancer in men [1] [2]. Prevention and successful treatment of the tumor pathology require the study of all risk factors and molecular mechanisms that influence progression of the disease.

Investigation of energy metabolism alterations accompanying malignant transformation of prostate tissue, is of current importance, since in epithelial cells of prostate peripheral zone (peripheral zone comprises $70 \%$ of the prostate gland, and $80 \%$ of malignant transformation occurs just on this segment) energy transformation occurs specifically, diversely from other types of cancers [3].

Most tumor cells demonstrate inefficient aerobic glycolysis with impaired Krebs cycle activity. Therefore, carcinogenesis in general is associated with metabolic transformation from energy efficient benign cells to energy inefficient cancer cells. Diversely from other Tumors, the complete activation of the Krebs cycle takes place (normally these cells reveal partial activity of the Krebs cycle because of high concentration of zinc) on the early stage of malignant transformation of the prostate glandular epithelium [1]. Correspondingly, the metabolic switch from energy inefficient prostate benign epithelial cells to energy efficient malignant ones occur [4]. Such changes of energy metabolism in epithelial cells of prostate cancer is the subject of high interest, however the mechanism of these changes has not been fully studied yet.

The optical spectroscopic methods are widely used in cancer research for today [5]. Nowadays, fluorescence spectroscopy, which can be used for in vivo evaluation of precancer and cancer processes, deserves special interest. This method is distinguished for being non-invasive, fast and highly informative. More than that, it can be used to evaluate such tissue characteristics, as cellular metabolism level, tissue vascularization, oxygen supply and histo-morphological changes [6]. The use of Laser Induced Fluorescence (LIF) as diagnostic method in clinical diagnostic is topical question for today [7].

The purpose of the presented work was to study the blood plasma and tumor tissue of men with prostate tumors by the laser induced fluorescence method.

\section{Materials and Methods}

For blood plasma fluorescence studies we have studied 4 groups: Patients with benign hyperplasia of the prostate (BHP), prostate benign hyperplasia with High Grade Prostate Intraepithelial Neoplasia (HGPIN), adenocarcinoma of prostate $(\mathrm{CaP})$ and control group consisted with practically healthy men.

For tumor tissue fluorescence studies we have also studied 4 groups: with benign hyperplasia of the prostate (BHP), benign hyperplasia of the prostate with inflammation, prostate benign hyperplasia with High Grade Prostate Intraepithelial Neoplasia (HGPIN) and adenocarcinoma of prostate (CaP). For all studied groups age of the patients was 60 - 75 at primary revealing of tumor and each group consisted of 15 patients.

The study was approved by the ethics committee of Georgia and blood and tissue samples were collected with informed consent from patients. Clinical stage of the disease was diagnosed by the A. Tsulukidze Urology National Centre of Georgia, by means of rectal, histological, and echographic examination of the prostate gland.

For blood plasma fluorescent measurements blood samples were taken before the surgery. For tissue fluorescence studies fresh tissue samples were gained during the transurethral resection of the prostate. All surgical operations were performed at the Urology National Centre of Georgia. After surgery, blood and tissue samples were immediately taken for LIF measurements ( 30 min from surgery).

Tumor slices for spectral investigation had the following dimensions: surface area of each tumor slice was 0.5 $1.0 \mathrm{~cm}^{2}$ and a few millimeters thick, not sectioned with any particular specificity. 2 or 3 cut tumor slices from each patient were taken.

Each sample was placed in a spectroscopic quartz minicuvettes $(1 \mathrm{~mm}$ path length, total volume $0.25 \mathrm{ml}$ ). These cuvettes were free of absorption and emission in the spectral range of interest, $330-500 \mathrm{~nm}$.

The same tissue samples were then subjected to post-spectroscopic histomorphological examination. Each tissue sample was placed in formalin (10\% neutral solution) after it was embeded in paraffin, sectioned (5 UM) 
and stained (i.e. hematoxylin and eosin). All the procedures were performed according to the standard procedures. Identification of high-grade PIN was done microscopically. Histomorphology of the tissue samples was carried out by uro-pathologist of the Urology National Centre, Georgia.

Statistical analysis of fluorescence spectra were performed by standard deviation method. P values $<0.05$ were considered to be statistically significant.

\section{The LIF Spectra Were Obtained by the Following Method}

Samples in spectroscopic quartz minicuvettes were exposed to $337 \mathrm{~nm} 10 \mathrm{~ns}$ pulses from a nitrogen laser at a repetition rate of $100 \mathrm{~Hz}$. The energy per pulse was $0.04 \mathrm{~mJ}$. Pulse duration was $10 \mathrm{~ns}$. The beam was focused into a spot $100 \mu \mathrm{m}$ in diameter at the front surface of the sample. For driving the laser beam sample was fixed on the translation stage with micrometric travel. Fluorescent emission was collected from the radiating surface spot by a system of lenses and focused on the entrance slit of an Oriel LineSpec CCD array spectrometer with an MS125TM spectrograph and data acquisition and control software. Emission spectra recorded from 300 to 600 nm were displayed on a PC monitor and stored as data files. About 2,000 measurements were made per spot per sample in these experiments [8] [9].

Normalization of tumor tissue spectra was performed by setting the peak intensity value to unity. For each tissue type (BHP, BHP with inflammation, BHP with HGPIN, or CaP) mean spectra were calculated from the recorded data inside the group.

\section{Results and Discussion}

\subsection{Blood Plasma Fluorescence Studies}

The aim of the work was to study the alterations of fluorescence intensities of plasma proteins and reduced nicotinamide coenzymes' corresponding I and II peaks in the blood of men with prostate tumors (BHP, BHP with HGPIN and $\mathrm{CaP}$ ) by the spectrofluorescent method in order to differentiate prostate tumors and establish the relationship between the blood spectra and metabolic changes that is characteristic to prostate tumor.

It's known that blood plasma spectrum of practically healthy men is characterised by two fluorescence peaks in ultraviolet and visible regions (Figure 1). According to the literary data, the first peak (340 - $360 \mathrm{~nm}$ ) corresponds to plasma proteins, and the second one $(440-460 \mathrm{~nm})$ to the reduced niconiamide coenzymes [10]. It must be mentioned here, that the intensity ratio of the first and second peaks represents significant characteristic of functional state of an organism [11]. The noticeable difference between the fluorescence spectra of control group and the spectra of the patients with prostate tumors has been detected. It has been revealed that in studied groups intensity of the first peak was increasing in the following manner: control group $\rightarrow$ BHP $\rightarrow$ BHP with HGPIN $\rightarrow$ prostate cancer (Figure 2). In the latter group the intensity of the plasma proteins' peak was especially high (Figure 2(d)). Literary data, as well as our previous investigations have shown that prostate tumors are characterized by dysproteinemia. Dysproteinemia is a clinical state characterized by abnormal, often excessive synthesis of plasma proteins associated with tumor growth (acute phase, DNA-binding and carcinoembryonic proteins) [12]. Furthermore, it's also known that content of $\alpha$ and $\beta$ globulines is increased [13] [14] and albumin level is decreased in blood plasma [15] [16]. Thus, increased levels of tumor specific proteins in blood of men with prostate tumors are in good accordance with our previuous works [17] and to literary data.

On the next stage of investigation direct dependance between the shape of the fluorescence spectra and the type of prostate tumor has been revealed. In particular, in case of blood plasma of men with BHP (Figure 2(b)) intensity of the second peak is sharply decreased compared with control. This fact may be due to the activation of certain NADH dependent enzyme systems (NADH-oxidases, NADH-dependent dehydrogenases, CytochromeP450 etc.) as the response of the organism to the formation of benign tumor and consequently to the enhanced consumption of reduced nicotinamide coenzymes [18]. It's also possible that during pathological condition (for example, benign hyperplasia of prostate) the metabolism of these substances goes in altered, destructive way.

Formation of prostate intraepithelial neoplastic (PIN) regions in prostate benign tumor tissue indicates the aggraviation of the disease. PIN is some kind of transitional form, when some regions of benign tumor turn to "malignant" ones. PIN is divided into two types or grades: low grade $\left(\mathrm{PING}_{1-2}\right)$ and high grade $\left(\mathrm{PING}_{3-4}, \mathrm{PING}_{5-6}\right)$ intraepithelial neoplasia. It is considered that in case of high grade PIN (HGPIN) benign tumor turns into malignant one after a certain period of time (3 - 5 years) [19].

Our investigations showed that in case of BHP with HGPIN (Figure 2(c)) the shape and intensity of the 


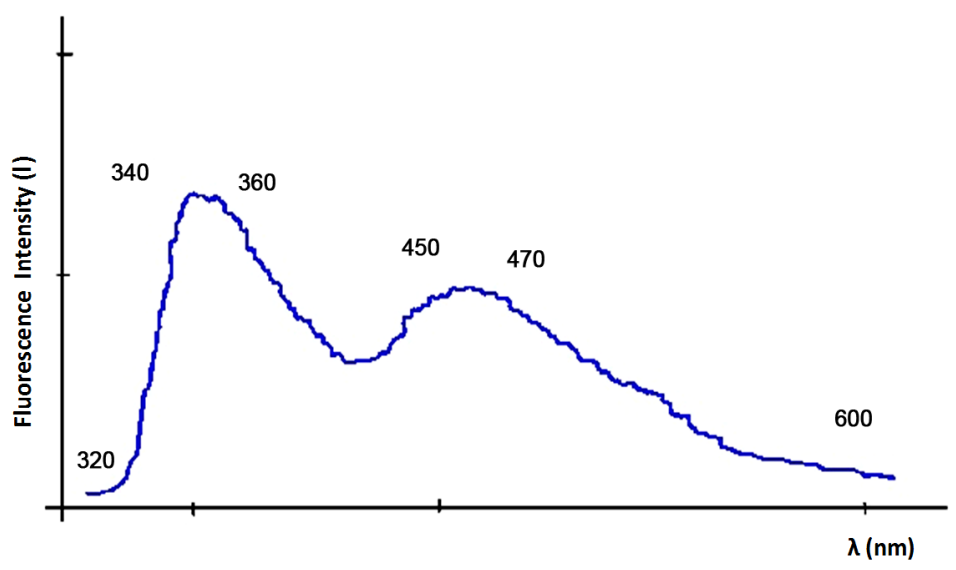

Figure 1. Fluorescence spectrum of the blood plasma of control group [10].

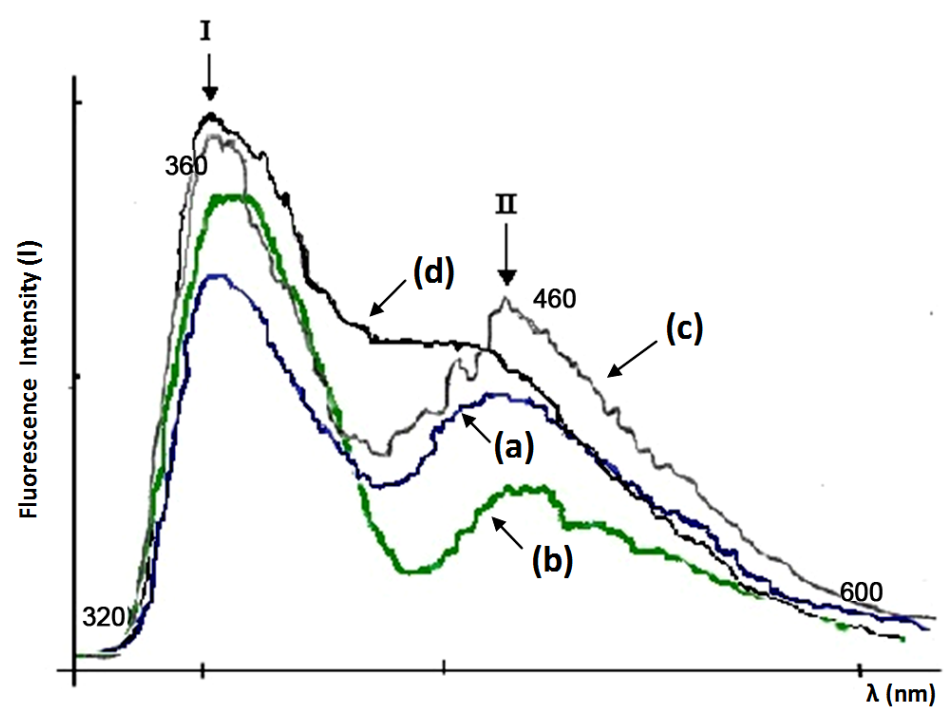

Figure 2. Fluorescence spectra of the blood plasma of men with prostate tumors. (a) Control group; (b) Benign hyperplasia of prostate; (c) Benign hyperplasia of prostate with HGPIN; (d) Adenocarcinoma of prostate.

second peak of the spectrum has changed. In particular, the peak took definite shape and the intensity has been sharply increased. As for the patients with prostate adeno carcinoma (Figure 2(d)) in the fluorescence spectrum of their blood plasma intensity of the second peak was noticeably increased compared with control group (Figure 2(a)) and the men with BHP (Figure 2(b)).

Accumulation of nicotineamide coenzymes (BHP with HGPIN, prostate adenocarcinoma) may be caused on the one hand by the disfunction of certain enzyme systems and their reduced activity during the progression of the disease [20] and by the changes of energy metabolism of tumor cells on the other [4].

It's known that prostate epithelial cells are characterized by the specific energy metabolism (diversely from other hormone-dependent tumors) [3]. The complete activation of the Krebs cycle takes place (normally these cells reveal partial activity of the Krebs cycle because of high concentration of zinc) on the early stage of malignant transformation of the prostate glandular epithelium [1]. Correspondingly, the metabolic switch from energy inefficient prostate benign epithelial cells to energy efficient malignant ones occur [1] [4].

From the above mentioned we suppose that restoration of complete functioning of Krebs cycle and respiratory chain should result in excess production and accumulation of NADH and NADPH in tumor tissue of men with BHP with HGPIN and prostate adenocarcinoma. This phenomenon in our investigations was detected by the incresed intensity of the second peak of the plasma spectrum. In case of prostate adenocarcinoma the change of 
the second peak shape and slight decrease of the peaks intensity, compared with BHP with HGPIN, may be due to the enhanced consumption of these coenzymes by the antioxidant systems of the prostate malignant cells [4]. This fact should point to the increased defense ability of the prostate malignant cells.

Our previous investigations have shown that in blood of men with prostate benign hyperplasia intensity of lipid peroxidation was increased ( 1,5-times) compared to control group. As for prostate adenocarcinoma, lipid peroxidation was sharply increased compared with men with BHP ( 1,7-times) and dramatically increased compared with control group ( 2,6-times).

Thus, we suppose that alterations of NADH dependent enzymes activity may be also caused by the change in lipid peroxidation intensity [20] This relation is also discussed in other recent works [21] [22]. Thus, accumulation of nicotinamide coenzymes and rise of the second peak of the spectrum, respectively, may also be due to the intensification of lipid peroxidation process.

\subsection{Tumor Tissue Fluorescence Studies}

Investigation of tumor tissues of the patients with prostate tumors using the fluorescence spectroscopy has revealed changes of the spectral shape and peaks of the obtained spectra, as well as intensities (I) of fluorescence.

The fluorescence spectrum of the tumor tissue of patients with benign hyperplasia of the prostate (Figure 3) has shown shoulder in the range of $390-400 \mathrm{~nm}$ of the spectrum $(\mathrm{I}=0.38)$, and the peak-in the range of 440 $460 \mathrm{~nm}(\mathrm{I}=0.48)$ (Table 1$)$.

We suppose that the shoulder in the range of 390 - $400 \mathrm{~nm}$ may correspond to the fluorescence of collagen [7], because collagen, as a structural protein and the major component of extracellular matrix, has emission in the range of $390-400 \mathrm{~nm}$. The $440-460 \mathrm{~nm}$ emission peak may correspond to the fluorescence of reduced nicotinamide coenzymes (NADH and NADPH), as the similar study results has shown [7] [23]. The above mentioned supposition is confirmed by the fact that, generally the autofluorescence of a tissue is induced by collagen, elastin and reduced nicotinamide coenzymes emissions [24] [25].

As for the tumor tissue of men with BHP with inflammation, here the fluorescence spectrum showed small peak at $400-410 \mathrm{~nm}(\mathrm{I}=0.55)$ and sharp peak at $440-460 \mathrm{~nm}(\mathrm{I}=0.87)$ (Figure 4, Table 1).

It is significant that in case of BHP with inflammation the intensity of fluorescence in the wavelength range of 440 - $460 \mathrm{~nm}$ was $\sim 2$ times higher, compared with benign tumor tissue. Furthermore, the shoulder (390 - $400 \mathrm{~nm}$ ) in benign tumor tissue was slightly moved towards a long wavelength in the spectrum (400 - $410 \mathrm{~nm})$ of benign tumor tissue with inflammation. As a result, we can see a small peak, the intensity of which was slightly raised.

The tumor tissue of men with BHP with HGPIN was studied at the next stage. The fluorescence spectrum of tissue of BHP with HGPIN showed again collagen related shoulder (390 - $400 \mathrm{~nm}$ ), which was slightly shifted to the $400-410 \mathrm{~nm}$ range. The intensity was notably raised in comparison with the benign tumor tissue $(\mathrm{I}=0.65)$. The peak at 440 - $460 \mathrm{~nm}$ was also noted $(\mathrm{I}=0.9)$ (Figure 5) (Table 1). It is notable that the intensity of fluorescence in the benign tumor tissue with HGPIN was $\sim 3$ times higher, than in the benign prostate tumor tissue.

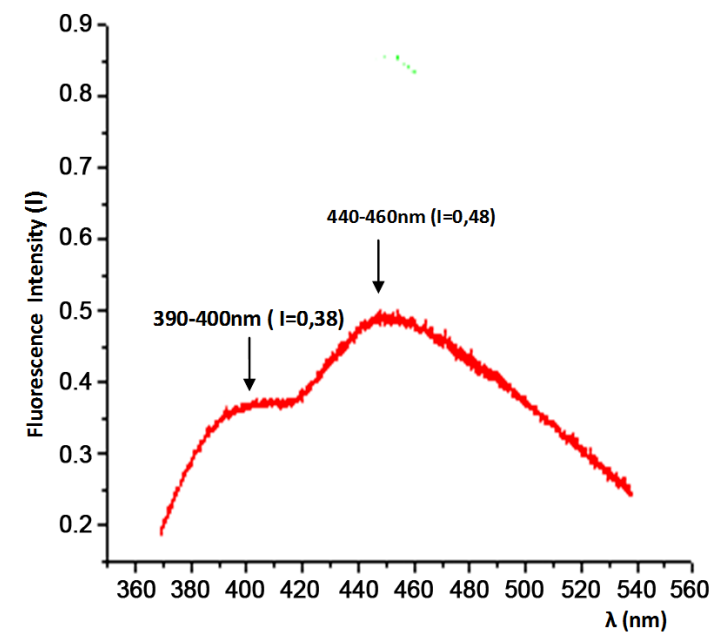

Figure 3. Mean fluorescence spectrum of the tumor tissue of men with benign hyperplasia of prostate. 
Table 1. Spectral parameters of tumor tissues fluorescence spectra of the men with prostate tumors.

\begin{tabular}{cccc}
\hline $\begin{array}{c}\text { Object } \\
\text { (tumor tissue) }\end{array}$ & $\begin{array}{c}\text { Shoulder } \\
\text { (wavelength, } \mathbf{n m} \text { ) }\end{array}$ & $\begin{array}{c}\text { Peak } \\
\text { (wavelength, nm) }\end{array}$ & $\begin{array}{c}\text { Fluorescence intensity } \\
\text { (I, relative units) }\end{array}$ \\
\hline Benign Hyperplasia of Prostate (BHP) & $390-400$ & $440-460$ & $0.38,0.48$ \\
BHP with Inflammation & & $400-410$ & $0.55,0.87$ \\
BHP with HGPIN & $400-410$ & $440-460$ & $0.65,0.9$ \\
Adenocarcinoma of Prostate & $400-410$ & $440-460$ & $0.45,0.8$ \\
\hline
\end{tabular}

$\mathrm{n}=15$ (the amount of the patients in each group).

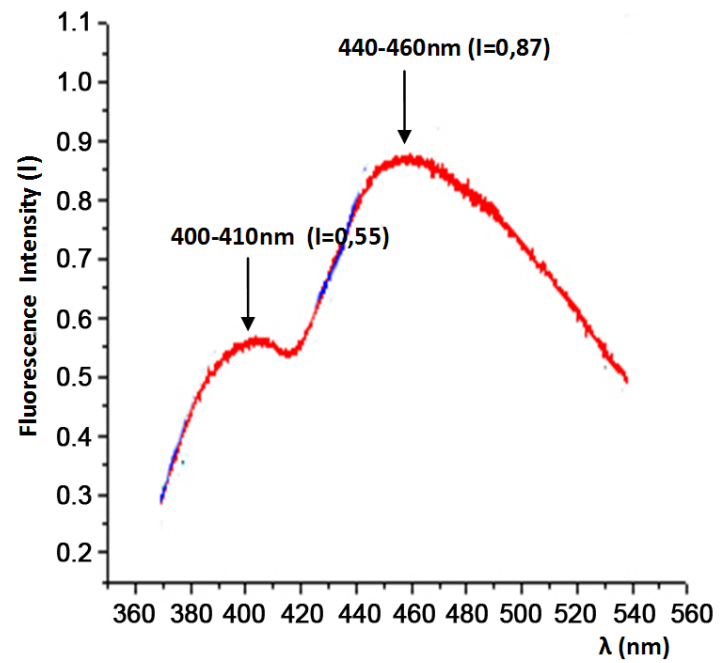

Figure 4. Mean fluorescence spectrum of the tumor tissue of men with benign hyperplasia of prostate with inflammation.

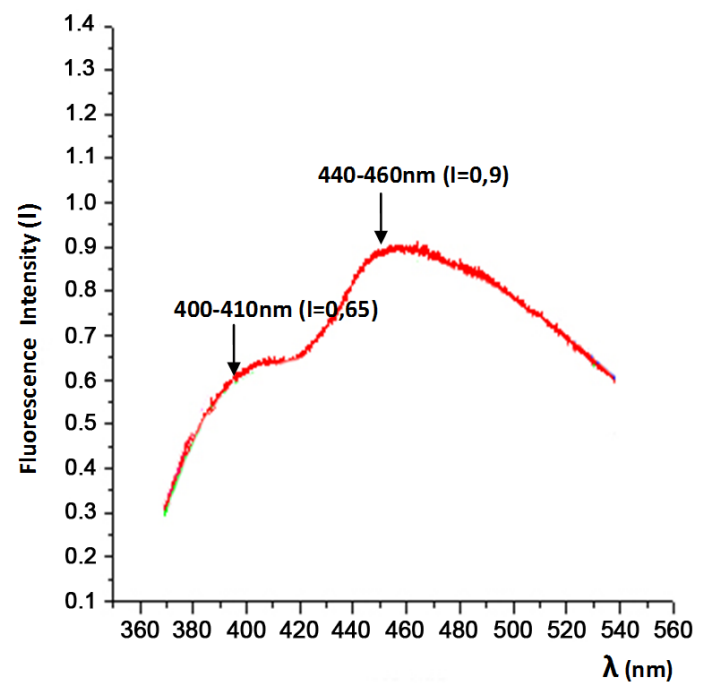

Figure 5. Mean fluorescence spectrum of the tumor tissue of men with benign hyperplasia of prostate with HGPIN.

The fluorescence spectrum of the tumor tissue of men with CaP showed slight shoulder at $400-410 \mathrm{~nm}(\mathrm{I}=$ 0.45) (Figure 6) and sharp peak, which is shifted towards long wavelength, diversely from previous spectra and was observed at $460-470 \mathrm{~nm}(\mathrm{I}=0.8$ ) (Table 1). It must be noticed that the slight shoulder at $400-410 \mathrm{~nm}$ conditioned with collagen also repeated in the spectrum of malignant prostate tumor tissue, but it was slightly 
shifted in comparison with the spectrum (390 - $400 \mathrm{~nm}$ ) of benign tumor tissue.

Normalization of all gained fluorescence spectra at $465 \mathrm{~nm}$ (Figure 7) clearly shown that each tissue sample is characterized with distinct spectral shape. The ratio of peaks maxima is also should be taken into account. So the gained tissue spectra are different not only by peak intensities, but also by the spectral line shape and ratio of peaks intensities.

The fluorescence spectra on the Figures 3-6, as well as normalized spectrum (Figure 7), demonstrate that the intensity of collagen peak increases following some dynamics: BHP $\rightarrow$ BHP with inflammation $\rightarrow$ BHP with HGPIN regions and it reaches its maximum in men with benign hyperplasia with HGPIN areas. It must be noticed that the intensity of collagen peak in case of $\mathrm{CaP}$ is a little less, than in the BHP with inflammation and BHP with HGPIN regions.

We suppose that in case of benign hyperplasia with HGPIN regions, the malignant regions, formed in benign tumor, need intensified biosynthesis of collagen to develop a stroma, typical for malignant tumor cells [26]. It's quite possible that in case of BHP with HGPIN regions observed peak at $400 \mathrm{~nm}$ indicates to the strong biosynthesis of the collagen [27]. As PIN regions have tendency to become malignant ones, it may be supposed that the accumulation of collagen in big amount represents some kind of preparation stage for the transformation process.

Increased intensity of nicotinamide coenzymes peak $(440-460 \mathrm{~nm})$ in parallel with the aggravation of disease $(\mathrm{BHP} \rightarrow \mathrm{BHP}$ with inflammation $\rightarrow$ BHP with HGPIN regions) should be the indication to increased amounts of these coenzymes. As for the sharp increase of nicotinamide coenzymes in benign tissue with HGPIN, this may be stipulated by the specific type of prostate tumor cells' metabolism, and corresponding sharp rise of activity of the Krebs cycle on the early stage of malignant transformation. The clear activation of the enzymes of mitochondrial glutathione-dependent system (GSH-Px, GR, GSH) during the malignant transformation, also indicates the increased amount of nicotinamide coenzymes [4]. It's known that functioning of this antioxidant system entirely depends on the concentration of nicotinamide coenzymes (NADH, NADPH) in the area [19].

The shift of the nicotinamide coenzymes peak (in the range of 460 - $470 \mathrm{~nm}$ ) and slight decrease of the intensity in case of prostate adenocarcinoma (Figure 6), compared with BHP with HGPIN, may be induced by the activation of glutathione-dependent enzymes (GSH-Px, GR) during malignant transformation process, and accordingly by intensified usage of reduced nicotinamide coenzymes. Considering the fact that the Krebs cycle doesn't function properly in prostate benign tumor epithelial cells, diversely from the case of prostate adenocarcinoma, only slight increase of the nicotinamide coenzymes amount may be assumed. This process was reflected by the minimal intensity of the coenzymes peak in the benign tumor tissue spectrum (Figure 3).

The change of the intensity of collagen peak of the fluorescence spectrum of prostate tumor tissue has been revealed. This perfectly reflects the structural changes, characteristic for malignant transformation of tumor tissue (intensified angiogenesis typical for malignant tumor, stroma development).

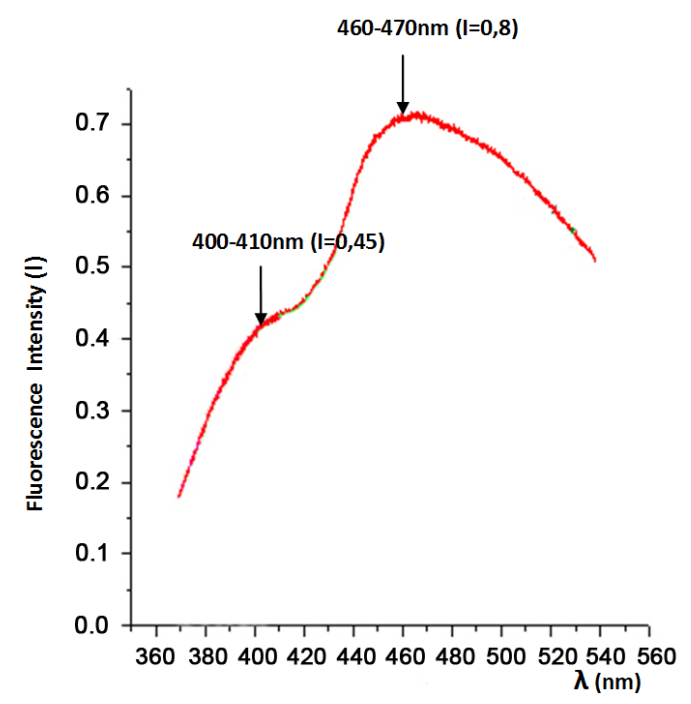

Figure 6. Mean fluorescence spectrum of the tumor tissue of men with prostate cancer. 


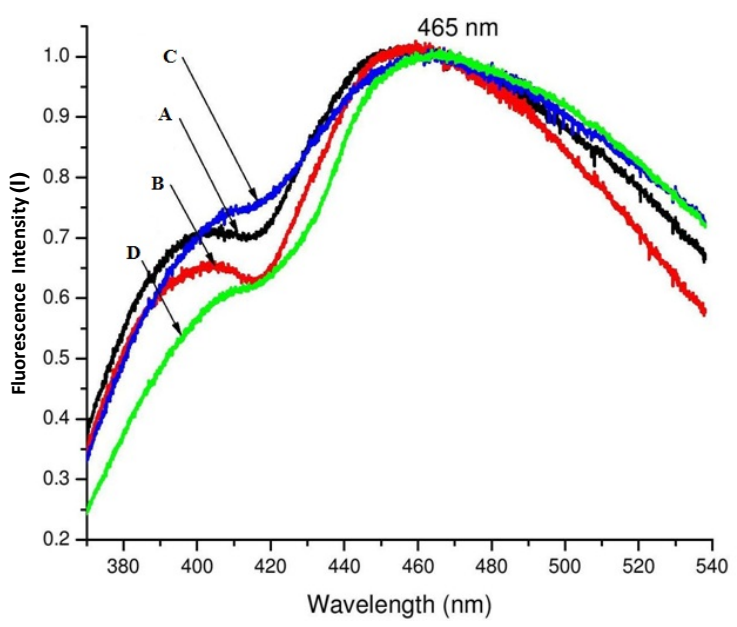

Figure 7. Normalized fluorescence spectra of the different tumor tissues of the men with prostate tumors. Fluorescence intensity normalized to unity at $\lambda=465 \mathrm{~nm}$. (A) Benign hyperplasia of prostate; (B) Benign hyperplasia of prostate with inflammation; (C) Benign hyperplasia of prostate with HGPIN; (D) Adenocarcinoma of prostate.

The peak of the reduced nicotinamide coenzymes and the change of its intensity in spectra of tumor tissue was revealed. Alteration of the peak intensity, characteristic for nicotinamide coenzymes, perfectly reflects and is in accordance with the specific energy metabolism, which should be the characteristic for prostate benign tumor on the one hand, and for prostate malignant tumor cells on the other.

Normalization of fluorescent spectra from different forms of prostate tumor tissues have shown that, each form has typical spectral line shape and ratio of peaks intensities. This approach presumably will enable us to differentiate prostate tumor tissues of different kind (especially prostate benign hyperplasia, prostate benign hyperplasia with HGPIN and prostate cancer).

\section{Conclusions}

Thus, fluorescence spectra of the blood plasma gives the possibility to study living system in vivo without destruction of the structural integrity and interruption of natural processes take place in organism. Furthermor, recorded spectra allow us to differentiate prostate tumors and judge the disease progression.

Alterations of nicotinamide coenzymes peak intensities perfectly reflect and are in accordance with the specific energy metabolism of prostate epithelial cells.

The change of the intensity of collagen peak, studied in tumor tissue fluorescence, fully reflects the structural changes, characteristic for malignant transformation of tumor tissue.

\section{Acknowledgements}

My appreciations go to the Institute of Cybernetics, Georgia—Prof. T. Medoidze and Prof. Z. Jaliashvili; Also my thanks go to the A. Tsulukidze Urology National Center of Georgia—Prof. Laurent Managadze, MD and Omar Tsintsadze, MD.

\section{References}

[1] Khandrika, L., Kumar, B., Koul, S., Maroni, P. and Koul, H.K. (2009) Oxidative Stress in Prostate Cancer. Cancer Letters, 282, 125-136. http://dx.doi.org/10.1016/j.canlet.2008.12.011

[2] Grivas, N., Hastazeris, K., Kafarakis, V., et al. (2012) Prostate Cancer Epidemiology in a Rural Area of North Western Greece. Asian Pacific Journal of Cancer Prevention, 13, 999-1002. http://dx.doi.org/10.7314/APJCP.2012.13.3.999

[3] Dakubo, G.D., Parr, R.L., Costello, L.C., Franklin, R.B. and Thayer, R.E. (2006) Altered Metabolism and Mitochondrial Genome in Prostate Cancer. Journal of Clinical Pathology, 59, 10-16. 
http://dx.doi.org/10.1136/jcp.2005.027664

[4] Kotrikadze, N., Alibegashvili, M., Ramishvili, L., Gordeziani, M., Veshapidze, N., et al. (2012) Mitochondrial Defects and Their Role in Development of Prostate Cancer. European Medical, Health and Pharmaceutical Journal, 3, 17-20.

[5] Dronova, O.B., Tretyakov, A.A., Mishchenko, A.N. and Bulgakova, N.N. (2008) Laser Induced Autofluorescence of Normal and Metaplasic Epithelium of Esophagogastric Transition at Gastroesophageal Reflux Disease. The Siberian Journal of Oncology, 4, 11-16.

[6] Ramanujam, N. (2000) Fluorescence Spectroscopy of Neoplastic and Non-Neoplastic Tissue. Neoplasia, 2, 89-117. http://dx.doi.org/10.1038/sj.neo.7900077

[7] Arshakyan, Kh.A., Pushkarev, S.V., Polovnikov, E.S. and Meshalkin, Yu.P. (2007) Diagnostic Facilities of Laser-Induced Fluorescence of Cervix Uteri Swabs in Case of Oncology Diseases. Bulletin of the Siberian Branch of the Russian Academy of Medical Sciences, 1, 30-34.

[8] Giorgadze, G.K., Jaliashvili, Z.V., Mardaleishvili, K.M., Medoidze, T.D. and Melikishvili, Z.G. (2006) Measurement of the Abnormality Degree in the Biological Tissue by the Laser Induced Fluorescence. Laser Physics Letters, 3, 8990. http://dx.doi.org/10.1002/lapl.200510056

[9] Jaliashvili, Z.V., Medoidze, T.D., Mardaleishvili, K.M., Ramsden, J.J. and Melikishvili, Z.G. (2008) Laser Induced Fluorescence Model of Human Goiter. Laser Physics Letters, 5, 217-219. http://dx.doi.org/10.1002/lapl.200710102

[10] Grigorovich, N.A., Slobozhanina, E.I., Monastyrnaia, P.L. and Chernitski, E.A. (1988) A Method of Diagnosing Malignant Neoplasms Based on the Natural Fluorescence of the Blood Serum in the Ultraviolet and Visible Regions of the Spectrum [Article in Russian]. Voprosy Onkologii, 34, 664-668.

[11] Borisenko, S.N., Kasymova, G.A. and Sorkin, V.M. (1988) Modified Albumin as a Diagnostic and Prognostic Test. Voprosy Onkologii, 34, 1123-1125. (In Russian)

[12] Grigorev, M.E., Stepensky, A.B. and Lebedev, D.V. (2002) Specific Antigens in Screening and Monitoring of the Patients with Prostate Cancer. Urology, 2, 50-53. (In Russian)

[13] Heeb, M.J. and España, F. (1998) $\alpha_{2}$-Microglobulin and C1-Inactivator Are Plasma Inhibitors of Human Glandular Kalikrein. Blood Cells, Molecules and Diseases, 24, 411-418. http://dx.doi.org/10.1006/bcmd.1998.0209

[14] Grigorev, M.E., Mazo, E.B., et al. (1998) Dynamics of the PSA and It's Molecular Forms with $\alpha_{1}$-Antichymotrypsin in Patients with Prostate Benign Hyperplasia. Urologia, 1, 33-36.

[15] Wajsman, Z. (2013) Prostate Cancer Recurrence-New Prognostic Factors Are Needed. Central European Journal of Urology, 66, 133-134.

[16] Nicholson, J.P., Wolmarans, M.R. and Park, J.R. (2000) The Role of Albumin in Critical Illness. British Journal of Anaesthesia, 85, 599-610. http://dx.doi.org/10.1093/bja/85.4.599

[17] Chigogidze, T., Bochorishvili, I., Alibegashvili, M., Zibzibadze, M., Ramishvili, L., Managadze, L., et al. (2009) Differential Scanning Microcalorimetric Investigation of Thermodynamic Parameters of the Blood Plasma in Men with Prostate Tumors. Urology, 74, S198-S199.

[18] Nawratil, P., Lenzen, S., Kellermann, J., Haupt, H., Schinke, T., Müller-Esterl, W., et al. (1996) Limited Proteolysis of Human $\alpha_{2}$-HS Glycoprotein/Fetuin. Journal of Biological Chemistry, 271, 31735-31741. http://dx.doi.org/10.1074/jbc.271.49.31735

[19] Zynger, D.L. and Yang, X. (2009) High-Grade Prostatic Intraepithelial Neoplasia of the Prostate: The Precursor Lesion of Prostate Cancer. International Journal of Clinical and Experimental Pathology, 2, 327-338.

[20] Kotrikadze, N., Alibegashvili, M., Zibzibadze, M., Abashidze, N., Chigogidze, T., et al. (2008) Activity and Content of Antioxidant Enzymes in Prostate Tumors. Experimental Oncology, 30, 1-4.

[21] Singh, R. and Pathak, D.N. (1990) Lipid Peroxidation and Glutathione Peroxidase, Glutathione Reductase, Superoxide Dismutase, Catalase, and Glucose-6-Phosphate Dehydrogenase Activities in $\mathrm{FeCl}_{3}$-Induced Epileptogenic Foci in the Rat Brain. Epilepsia, 31, 15-26. http://dx.doi.org/10.1111/j.1528-1157.1990.tb05354.X

[22] Ondei, L.S., Silveira, L.M., Leite, A.A., Souza, D.R., Pinhel, M.A., Percário, S., et al. (2009) Lipid Peroxidation and Antioxidant Capacity of G6PD-Deficient Patients with A-(202G > A) Mutation. Genetics and Molecular Research, 8, 1345-1351. http://dx.doi.org/10.4238/vol8-4gmr662

[23] Schomacker, K.T., Frisoli, J.K., Compton, C.C., Flotte, T.J., Richter, J.M., Nishioka, N.S., et al. (1992) Ultraviolet Laser-Induced Fluorescence of Colonic Tissue: Basic Biology and Diagnostic Potential. Lasers in Surgery and Medicine, 12, 63-78. http://dx.doi.org/10.1089/pho.2008.2255

[24] Chowdary, M.V., Mahato, K.K., Kumar, K.K., Mathew, S., Rao, L., Krishna, C.M., et al. (2009) Autofluorescence of Breast Tissues: Evaluation of Discriminating Algorithms for Diagnosis of Normal, Benign, and Malignant Conditions. Photomedicine and Laser Surgery, 27, 241-252. http://dx.doi.org/10.1089/pho.2008.2255

[25] Lu, S.C. (2009) Regulation of Glutathione Synthesis. Molecular Aspects of Medicine, 30, 42-59. 
http://dx.doi.org/10.1016/j.mam.2008.05.005

[26] Zhang, Y., Tang, J., Liang, H.D., Lv, F.Q. and Song, Z.G. (2014) Transrectal Real-Time Tissue Elastography—An Effective Way to Distinguish Benign and Malignant Prostate Tumors. Asian Pacific Journal of Cancer Prevention, 15, 1831-1835. http://dx.doi.org/10.7314/APJCP.2014.15.4.1831

[27] Chissov, V.I., Sokolov, V.V., Bulgakova, N.N. and Filonenko, E.V. (2003) Fluorescence Endoscopy, Dermascopy and Spectrophotometry for Diagnosis of Malignant Tumors. Russian Journal of Biotherapy, 2, 45-56. 
Scientific Research Publishing (SCIRP) is one of the largest Open Access journal publishers. It is currently publishing more than 200 open access, online, peer-reviewed journals covering a wide range of academic disciplines. SCIRP serves the worldwide academic communities and contributes to the progress and application of science with its publication.

Other selected journals from SCIRP are listed as below. Submit your manuscript to us via either submit@scirp.org or Online Submission Portal.
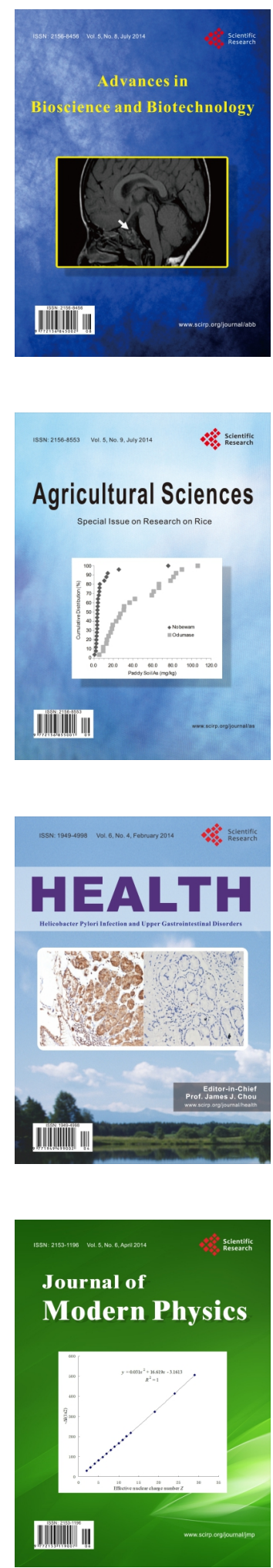
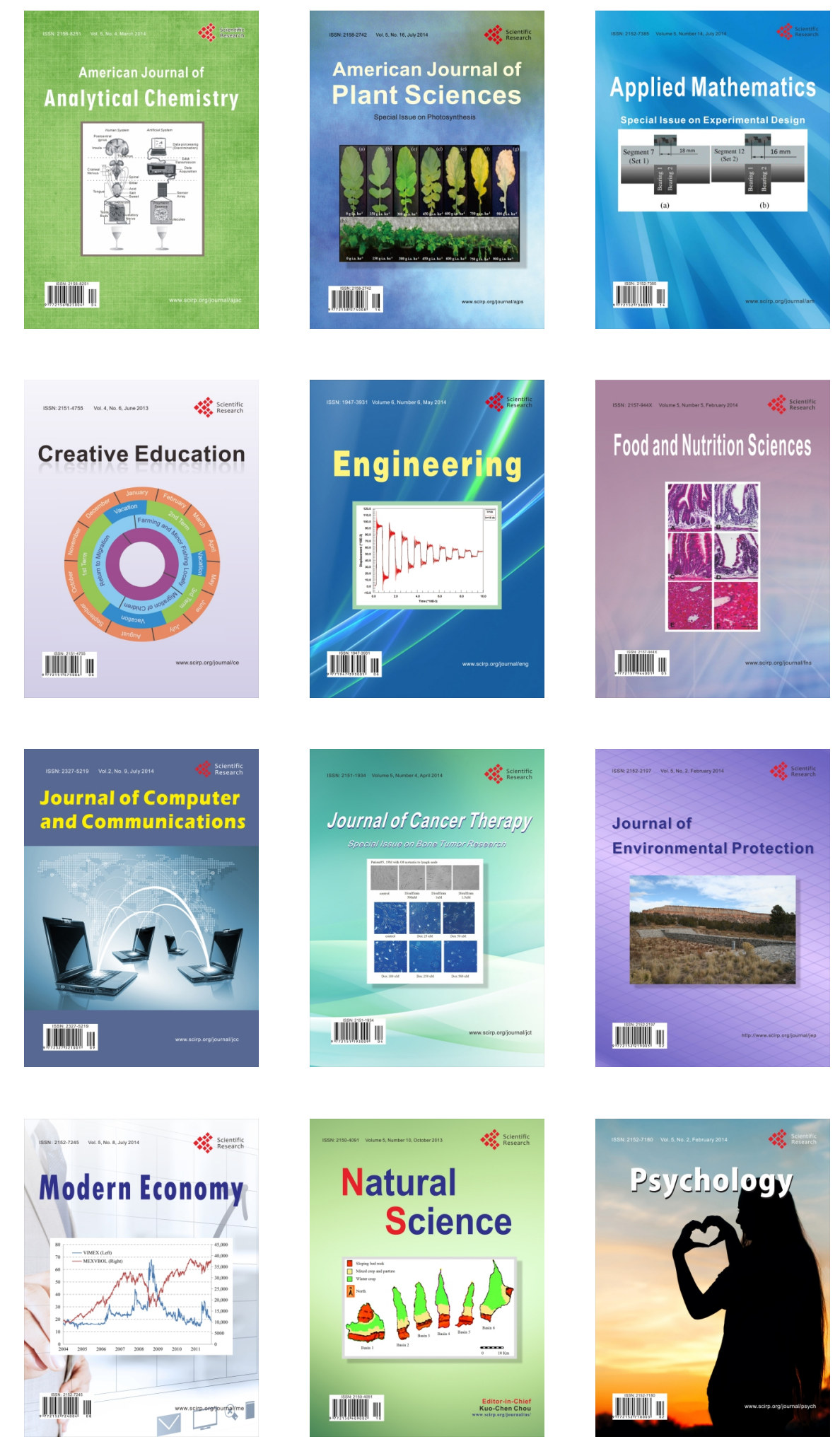